\title{
Cannabinoids and pain
}

\author{
J Michael Walker PhD*, Nicole M Strangman PhD, Susan M Huang BS
}

\section{JM Walker, NM Strangman, SM Huang. \\ Cannabinoids and pain. \\ Pain Res Manage 2001;6(2):74-79.}

Cannabinoids have been used to treat pain for many centuries. However, only during the past several decades have rigorous scientific methods been applied to understand the mechanisms of cannabinoid action. Cannabinoid receptors were discovered in the late 1980s and have been found to mediate the effects of cannabinoids on the nervous system. Several endocannabinoids were subsequently identified. Many studies of cannabinoid analgesia in animals during the past century showed that cannabinoids block all types of pain studied. These effects were found to be due to the suppression of spinal and thalamic nociceptive neurons, independent of any actions on the motor systems. Spinal, supraspinal and peripheral sites of cannabinoid analgesia have been identified. Endocannabinoids are released upon electrical stimulation of the periaqueductal gray, and in response to inflammation in the extremities. These observations and others thus suggest that a natural function of cannabinoid receptors and their endogenous ligands is to regulate pain sensitivity. The therapeutic potential of cannabinoids remains an important topic for future investigations, with previous work suggesting utility in clinical studies of cancer and surgical pain. New modes of delivery and/or new compounds lacking the psychotropic properties of the standard cannabinoid ligands offer promise for cannabinoid therapeutics for pain.

Key Words: Analgesia; Anandamide; Endocannabinoid; Cannabinoid; Pain; Receptor

\section{Les cannabinoïdes et la douleur}

RÉSUMÉ : Les cannabinoïdes servent depuis des siècles à soulager la douleur. Cependant, ce n'est que depuis quelques décennies qu'on applique des méthodes scientifiques rigoureuses pour comprendre les mécanismes d'action de ces substances. Les récepteurs des cannabinoïdes ont été découverts à la fin des années 1980 et ils médient l'effet de ces substances sur le système nerveux. L'existence de plusieurs endocannabinoïdes a, par la suite, été confirmée. Selon de nombreuses études menées au siècle dernier sur l'analgésie chez les animaux, les cannabinoïdes bloquent tous les types de douleur examinés. Le blocage s'explique par la suppression de l'activité des neurones nociceptifs rachidiens et thalamiques, indépendamment de leur action sur le système nerveux moteur. Des foyers d'analgésie aux cannabinoïdes ont été trouvés dans différentes régions : spinale, supraspinale, périphérique. La stimulation électrique de la substance grise péri-épendymaire du mésencéphale et l'inflammation des extrémités provoquent la libération d'endocannabinoïdes. Ces observations, jointes à d'autres, semblent indiquer qu'une des fonctions naturelles des récepteurs des cannabinoïdes et de leurs ligands endogènes est de réguler la sensibilité à la douleur. Les propriétés thérapeutiques potentielles des cannabinoïdes susciteront encore beaucoup de recherches, compte tenu des résultats de travaux antérieurs laissant entrevoir leur utilité dans les études cliniques sur le cancer et la douleur postopératoire. De nouveaux modes d'administration ou de nouveaux composés dépourvus des effets psychotropes des ligands cannabinoïdes usuels s'avèrent prometteurs pour le soulagement de la douleur par ces substances.

Departments of Psychology and Neuroscience, Brown University, Providence, Rhode Island, USA

Correspondence and reprints: Dr J Michael Walker, Brown University, Department of Psychology, 89 Waterman St, PO Box 1853, Providence, Rhode Island 02912, USA. Telephone 401-863-2048,fax 401-863-1300, email j_walker@brown.edu

*Dr Walker is Professor of Psychology, Neuroscience and Neuropharmacology at Brown University in Providence, Rhode Island. He is a leading expert on the role of cannabinoids in pain and motor function. He has been researching the central modulation of nociceptive systems since the 1970s. Dr Walker is recognized for elucidating neural mechanisms of cannabinoid analgesia and identifying a role for endocannabinoids in pain modulation and motor function. Dr Walker is recipient of a Research Scientist Career Award from the National Institute of Health and is President of the International Cannabinoid Research Society 
$\mathrm{C}$ annabinoids are compounds that exhibit a pharmacological profile similar to that of delta $^{9}$-tetrahydrocannabinol $\left(\Delta^{9}-\mathrm{THC}\right)$, the main psychoactive principle found in marijuana. Cannabinoids have been used to treat pain for many centuries (reviewed in 1). Early uses included surgical anesthesia in China, amelioration of childbirth pain in ancient Israel, and as an analgesic in Asia throughout the middle ages and for a variety of painful ailments in the West during the 1800 s, with commercial preparations supplied by Lilly and Squibb. For a variety of reasons, political and pharmacological (eg, the instability of cannabis extracts, unpredictable absorption and insolubility in water), cannabinoids were discontinued as medical agents in the 1930s.

\section{NEUROBIOLOGY OF CANNABINOID ANALGESIA}

Preclinical studies in animals revealed that cannabinoids block pain responses in every pain model tested. Perhaps the earliest study of this type was performed by Walter E Dixon (2), one of the fathers of modern pharmacology, who demonstrated that cannabinoids suppress canine reactions to pinpricks. Early studies by Bicher and Mechoulam (3), and Kosersky et al (4) paved the way for many subsequent studies that verified the ability of cannabinoids to suppress profoundly the behavioural reactions to noxious stimuli, inflammation and nerve injury. In models of acute or physiological pain, cannabinoids are highly effective against thermal (5-9), mechanical (10) and chemical pain $(10,11)$. Typically, cannabinoids were comparable with opiates both in their potency and in their efficacy $(6,12)$. In models of tonic or chronic pain, both inflammatory (13) and neuropathic (14), cannabinoids show even greater potency and efficacy.

Nevertheless, difficult issues related to the pharmacology of cannabinoids hampered the acceptance of cannabinoids as analgesics. The two main drawbacks were the lack of understanding of the molecular pharmacology of these compounds and the possibility that cannabinoids produced behavioural suppression in pain models by effects on the motor system. These concerns have been addressed in recent years. The following sections briefly review the rapid advances in these areas.

\section{MOLECULAR PHARMACOLOGY OF CANNABINOIDS}

Before the late 1980s, cannabinoids were thought to affect the nervous system by perturbing neuronal membranes. These highly lipophilic compounds were presumed to dissolve in the cell membrane, thereby altering its function in a nonspecific manner. Advances in the development of high specific activity radioligands that permitted identification of neurotransmitter receptors for many classes of drugs proceeded slowly with cannabinoids. The main obstacle was that these compounds affiliate with neuronal membranes, making the identification of receptors almost impossible with traditional drugs. This problem was overcome when Devane et al (15) at St Louis University, St Louis, Missouri, employed a labelled version of a new drug developed by
Pfizer (USA), CP55940, to demonstrate the existence of cannabinoid receptors on brain membranes. Matsuda and co-workers (16) at the National Institutes of Health cloned the receptor, which proved to be a $\mathrm{G}$ protein-coupled receptor, now called $\mathrm{CB} 1$ to differentiate it from another subtype discovered later called CB2 (17). The CB1 subtype is found in the nervous system, spleen and testes (18-20; reviewed in 21 ), while the CB2 subtype is absent from neural tissues and is located in immune tissues such as the spleen, tonsils, monocytes, B cells and T cells $(17,22,23$; reviewed in 21$)$.

Cannabinoids alter neurotransmission through CB1 receptors by inhibition of P/Q-type calcium channels (24), inhibition of adenylyl cyclase (25) and activation of potassium channels and mitogen-activated protein (MAP) kinase (reviewed in 21). The overall effect is cellular inhibition. CB2 receptors do not appear to gate ion channels, but they inhibit adenylyl cyclase and activate MAP kinase.

The distribution of cannabinoid CB1 receptors in the brain has been examined by receptor autoradiography, immunohistochemistry and in situ hybridization histochemistry (18-20). These papers revealed that cannabinoid receptors are frequently localized to nerve endings, serving as presynaptic inhibitors of neurotransmitter release. Presynaptic inhibition is a particularly powerful mechanism of neural modulation because it can have the final determinant influence on the output signal of a neuron and its subsequent communication to other neurons. The highest levels of cannabinoid receptors are found in the hippocampus, the basal ganglia and the cerebellum - areas predominantly associated with memory and motor coordination. The low level found in brainstem cardiorespiratory centres probably accounts for the extremely high safety margin of the compounds. To date, there have been no deaths known to have resulted from overdose of marijuana.

Cannabinoid receptors also occur in high density in many areas related to pain. They densely populate the periaqueductal gray (PAG) and the rostral ventrolateral medulla $(\mathrm{RVM})$ - brain areas involved in descending pain modulation. They are concentrated in the superficial layers of the spinal dorsal horn, and they are found in the dorsal root ganglion, from where they are transported to both central and peripheral terminals of primary afferent neurons $(18,26-29)$. These areas provide peripheral, spinal and central targets through which cannabinoids modulate pain.

\section{Endocannabinoids}

The discovery of the cannabinoid receptors begged the question of whether the brain produces marijuana-like substances (called 'endocannabinoids'). In short order, Devane and co-workers (30) identified $N$-arachidonylethanolamine, an endogenous mediator, and named the compound anandamide, from the Sanskrit word 'ananda', which translates roughly as 'internal bliss'. A second endocannabinoid, $N$-arachidonylglycerol, was identified by Mechoulam and colleagues (31) and Sugiura's group (32). Both compounds exhibit affinity for both $\mathrm{CB} 1$ and $\mathrm{CB} 2$ receptors. The subject of their roles in pain will be addressed below. 


\section{MOTOR EFFECTS OF CANNABINOIDS}

Cannabinoid receptors densely populate the terminals of striatal output neurons that innervate the globus pallidus and the substantia nigra. By presynaptic inhibition, activation of these receptors blocks the communication between corticostriatal neurons and the output of the basal ganglia (reviewed in 33). At high doses in animal studies, this produces an odd condition called catalepsy, a state characterized by frozen postures and immobility. Although the effects of cannabinoids on movement are complex (both inhibition and activation can occur depending on the dose), this hypoactivity produced at higher doses of cannabinoids raised the concern that, even at doses where frank motor disability is not evident, the slowed reactions of animals in pain tests may have resulted from motor dysfunction rather than pain inhibition.

\section{EFFECTS OF CANNABINOIDS ON NOCICEPTIVE NEURONS}

Until 1990, virtually nothing was known about the effects of cannabinoids on the neural pathways that transmit pain messages from the spinal cord to the brain, and the determination of whether cannabinoids actually affect nociceptive neurotransmission was a crucial missing link in the developing story on cannabinoids and pain, due to the problems discussed above. Therefore, we undertook a series of studies that examined the effects of cannabinoids on noxious stimulation-produced activity in nociceptive spinal and thalamic neurons (34-39). In these studies, extracellular single neuron recordings were obtained from anesthetized rats, and the responses of both nociceptive neurons and non-nociceptive neurons to a variety of stimuli were studied. In many experiments (Figure 1), cannabinoids produced profound suppression of cellular nociceptive responses. A summary of the findings of a series of experiments indicates that cannabinoids exhibit the following characteristics.

- High potency (effects observed at approximately $75 \mu \mathrm{g} / \mathrm{kg}$, intravenously)

- High efficacy (typically greater than $80 \%$ reduction in response to noxious stimulation)

- Effects are CB1 receptor-mediated

- Suppression of both wide dynamic range neurons (respond to touch and pain) and nociceptive-specific neurons (respond to pain only)

- No suppression of low threshold mechanoreceptive neurons (respond to touch only)

- Spinal and thalamic neurons affected similarly

- Suppression of behavioural and neurophysiological responses to all types of nociceptive stimuli tested

- Behavioural analgesic time course and potency highly correlated with neuronal suppression of nociceptive stimulus-evoked activity

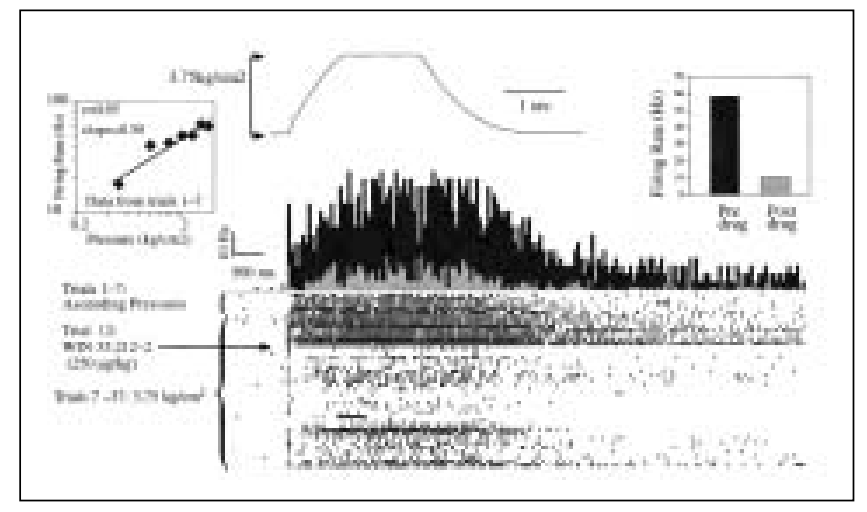

Figure 1) Example of inhibition of evoked activity in a wide dynamic range neuron by the cannabinoid WIN 55,212-2. The responses of the neuron to mechanical pressure were examined during 37 trials corresponding to each row of dots in the raster plot (top row = trial 1). Each dot represents the time of occurrence of a single action potential relative to the stimulus onset. Trials 1 to 7 consisted of applications of increasingly strong mechanical stimulation ranging from non-noxious to noxious levels $\left(0.5,1,1.5,2,2.5,3\right.$ and $\left.3.75 \mathrm{~kg} / \mathrm{cm}^{2}\right)$. The concomitant increases in density of dots under the stimulus in the first seven rows are indicative of the increasingly strong response of the neuron. Left (inset) The mean firing rates of the neuron during a graded series of stimulations are plotted (log-log coordinates) against the applied pressure. The neuron's systematic change in responsiveness was the basis for classifying this cell as a wide dynamic range neuron. Centre The noxious stimulus illustrated by the pressure waveform (top centre) was administered every $2 \mathrm{~min}$ for trials 7 to 37 . Trials 8 to 12 constituted baseline trials; after trial 12 (arrow), WIN 55,212-2 (250 mg/kg, intravenous) was administered. A marked decrease in the responsiveness of the neuron is indicated by the sharply decreased density of dots in subsequent rows of the raster plot. Right (inset) Comparison of the mean firing rate during the stimulus for the five baseline trials to the firing rate during the stimulus for the first 10 postinjection trials illustrating, approximately, an $82 \%$ decrease in responsiveness. The black peristimulus time histogram between the raster plot and the pressure waveform represents the baseline firing rate before injection, whereas the grey peristimulus time histogram represents the firing rate for the first 10 postinjection trials

- Suppression of windup (a model of central sensitization that is observed in chronic pain)

- Suppression of increased spontaneous firing following complete Freunds adjuvant (CFA) - an inflammatory agent

The first eight bullets reflect effects on nociceptive or physiological pain, whereas the last two employ chronic pain models. In windup, we studied the increasing response of neurons to trains of $\mathrm{C}$ fibre strength electrical stimulation (39), and the CFA experiments examined responses to an inflammatory stimulus. The results of these experiments are consistent with those of the behavioural tests discussed above, which showed that cannabinoids are active in models of inflammatory and neuropathic pain. This is important because these models are better indicators of the therapeutic potential of cannabinoids than tests of physiological (acute) pain. 


\section{SITES OF ACTION OF CANNABINOIDS}

Although the studies discussed above demonstrated the ability of cannabinoids to suppress nociceptive neurotransmission, one must ask about the site of action of the drugs. Ostensibly, the cannabinoids could produce analgesia by an action in the brain via descending modulation, by a direct spinal action and/or by an action on the peripheral nerve. The consensus from studies conducted in a number of different laboratories is that cannabinoids exert effects at all three locations.

Early studies from our laboratory indicated that cannabinoids, administered intracerebroventricularly, suppress tailflick responses (40) and spinal nociceptive responses in rats (36). This effect occurs at low doses, and further studies using direct brain injections indicated that the antinociceptive effects can be elicited from at least seven different brain areas, which include the dorsal PAG in the midbrain, the RVM and the noradrenergic nucleus A5 in the medulla (4143). All of these areas participate in descending inhibition of spinal nociceptive projection pathways (44). Work from Meng et al (45) showed that cannabinoids exert marked effects on neurons in the RVM, a site active in descending suppression of spinal nociceptive neurons. It is clear, therefore, that cannabinoids produce antinociceptive effects by descending spinal inhibition.

Endocannabinoids appear to participate in endogenous pain modulation by actions in the PAG. Work from our laboratory showed that blocking the cannabinoid $\mathrm{CB} 1$ receptor by the antagonist SR141716A produces hyperalgesia in the formalin test, and blocks the analgesia produced by electrical stimulation of the dorsal PAG (46). These findings confirmed those of Richardson et al (47-49), who found that this cannabinoid antagonist, injected intrathecally, produced hyperalgesia, and that the same effect occurs with spinal CB1 receptor knockdown. The pronociceptive actions of the antagonist are reasonable evidence for an antinociceptive action of one or more endocannabinoids.

To address directly the questions regarding the role of endocannabinoids that were made inferentially from the actions of an antagonist, we took the further step of measuring endocannabinoids in the PAG using microdialysis (50). This method permits collection of neurotransmitters/modulators from the extracellular space, and is, therefore, an indicator of the release of these modulators. Using liquid chromatography/mass spectrometry, we were able to establish that the analgesia produced by electrical stimulation or injections of the chemical irritant formalin into the hindpaws of anesthetized rats induced the release of anandamide in the PAG. Thus it appears that either pain itself, or electrical stimulation leads to the release of anandamide, which acts on cannabinoid receptors in the PAG to inhibit nociception.

Yaksh (9), and later Welch and Stevens (51), and others $(7,8,35,47-49)$ showed that cannabinoids inhibit pain in part by a direct spinal action. These observations are consistent with the dense labelling by $\mathrm{CB} 1$ receptor antibodies or $\mathrm{CB} 1$ receptor radioligands of cannabinoid receptors in the superficial and deep layers of the dorsal horn. Direct spinal appli- cation of cannabinoids inhibits the nociceptive responses of spinal nociceptive neurons.

Recent work also indicates an action of cannabinoids in the periphery. Injections of low doses of anandamide into an area of inflammation in the paw produced by carageenan reduced the ensuing hyperalgesia. This finding is consistent with the presence of cannabinoid receptors in the peripheral nerve and their transport to the distal endings (52). Subsequent work by Calignano et al (53) showed that endocannabinoids acting in the periphery may modulate pain responses.

\section{CLINICAL IMPLICATIONS}

It is notable that the debate surrounding medical marijuana is not whether cannabinoids can be marketed as therapeutic agents, as several approved drugs are currently available: dronabinol (Marinol; Sanofi-Synthelabo, Canada) ( $\Delta^{9}$-THC) and nabilone (levonantradol, a THC analogue) are currently available by prescription. Rather, the debate is on whether smoking of medicines should be permitted, and whether the crude plant material may have some effects that differ from those of synthetic $\Delta^{9}$-THC.

Because smoking is associated with grave health risks, it is an undesirable drug delivery system. Recognizing this fact, the United States National Academy of Sciences Institute of Medicine recommended that therapeutic uses of smoked marijuana be highly regulated and reserved for dire circumstances (54). Because it is readily available and may be useful against pain, why not simply prescribe dronabinol? While in some cases this may be a reasonable strategy, the utility of dronabinol is hindered by its slow and unpredictable absorption. This is a serious drawback because, although an overdose of dronabinol would almost certainly not be lethal, it does produce dysphoria at sufficiently high doses. Indeed, this characteristic of cannabinoids is the main limiting factor in dosing, so that the prototypical compounds may well produce unwanted side effects at doses lower than the maximal analgesic effects. Nevertheless, oral $\Delta^{9}$-THC was roughly equivalent to codeine in studies of cancer pain $(55,56)$ and produced analgesia without severe side effects in a relatively narrow range of doses. When given intravenously, THC was also found to be effective for the treatment of surgical pain (57). Furthermore, several laboratories are developing other drug delivery systems that should provide faster, more reliable bioavailability of the drug.

Another feature of cannabinoid pharmacology that should be noted is the possibility that the unwanted side effects can be dissociated from the therapeutic effects. One example of this may be found in the experimental compound ajulemic acid ( $1^{\prime}, 1^{\prime}$ dimethylheptyl- $\Delta^{8}-\mathrm{THC}-11-$ oic acid, CT-3). This compound, which is under development by Atlantic Technology Ventures Inc (USA) produces analgesia, but it is almost entirely lacking in side effects in animals (58). This analgesic effect is blocked by the CB1 receptor antagonist SR141716A. Yet this compound exerts only modest inhibition of adenylyl cyclase via the CB1 receptor (59). This finding coincides with emerging reports 
that cannabinoid agonists are capable of differential stimulation of different $\mathrm{G}$ proteins, resulting in different alterations in cell physiology. It is conceivable that the neurons that mediate pain inhibition may require one signal transduction pathway, while those that mediate dysphoria require another. Many questions about this and similar compounds are awaiting further research, but this appears to be a line of inquiry that may bear fruit.

Another direction worthy of more research lies in the potential therapeutic value of drugs that would enhance the activity of endocannabinoids. We once envisioned pain therapies that operated by mobilization of endogenous opioids. The disappointing results of much work in this area stemmed largely from the fact that peptide synthesis and inactivation processes are so similar among all peptides that selective agents for these neuromodulators never became available. By contrast, the known endocannabinoids are synthesized and degraded by what now appear to be rela-

\section{REFERENCES}

1. Iversen LL. The Science of Marijuana. Oxford: Oxford University Press, 2000.

2. Dixon WE. The pharmacology of cannabis. Indica Br Med J 1899;2:1354-7.

3. Bicher HI, Mechoulam R. Pharmacological effects of two active constituents of marihuana. Arch Int Pharmacodyn Ther 1968;172:24-31.

4. Kosersky DS, Dewey WL, Harris LS. Antipyretic analgesic and antiinflammatory effects of delta 9-tetrahydrocannabinol in the rat. Eur J Pharmacol 1973;24:1-7.

5. Buxbaum DM. Analgesic activity of $\Delta^{9}$-tetrahydrocannabinol in the rat and mouse. Psychopharmacol 1972;25:275-80.

6. Bloom AS, Dewey WL, Harris LS, Brosius KK. 9-nor-9 $\beta$-hydroxyhexahydrocannabinol, a cannabinoid with potent antinociceptive activity: comparisons with morphine. J Pharmacol Exp Ther 1977;200:263-70.

7. Lichtman AH, Martin BR. Spinal and supraspinal components of cannabinoid-induced antinociception. J Pharmacol Exp Ther 1991;258:517-23.

8. Lichtman AH, Martin BR. Cannabinoid-induced antinociception is mediated by a spinal $\alpha_{2}$-noradrenergic mechanism. Brain Res 1991;559:309-14.

9. Yaksh TL. The antinociceptive effects of intrathecally administered levonantradol and desacetyllevonantradol in the rat. J Clin Pharmacol 1981;21:334S-40S.

10. Sofia RD, Nalepa SD, Harakal JJ, Vassar HB. Anti-edema and analgesic properties of $\Delta^{9}$-tetrahydrocannabinol THC. J Pharmacol Exp Ther 1973;186:646-55.

11. Formukong EA, Evans AT, Evans FJ. Analgesic and antiinflammatory activity of constituents of Cannabis sativa L. Inflammation 1988; 12:361-71.

12. Jacob J, Ramabadran K, Campos-Medeiros M. A pharmacological analysis of levonantradol antinociception in mice. J Clin Pharmacol 1981;21:327S-33S

13. Tsou K, Lowitz KA, Hohmann AG, et al. Suppression of noxious stimulus-evoked expression of fos-like immunoreactivity in rat spinal cord by a selective cannabinoid agonist. Neuroscience 1995;70:791-8.

14. Herzberg U, Eliav E, Bennett GJ, Kopin IJ. The analgesic effects of $\mathrm{R}(+)$-WIN 55,212-2 mesylate a high affinity cannabinoid agonist, in a rat model of neuropathic pain. Neurosci Lett 1997;221:157-60.

15. Devane WA, Dysarz FA III, Johnson MR, Melvin LS, Howlett AC. Determination and characterization of a cannabinoid receptor in rat brain. Mol Pharmacol 1988;4:605-13.

16. Matsuda LA, Lolait SJ, Brownstein MJ, Young AC, Bonner TI. Structure of a cannabinoid receptor and functional expression of the cloned cDNA. Nature 1990;346:561-4.

17. Munro S, Thomas KL, Abu-Shaar M. Molecular characterization of a peripheral receptor for cannabinoids. Nature 1993;365:61-5. tively selective enzymes, and a selective transporter for the reuptake of anandamide has been identified (reviewed in $21,60,61)$. These findings raise the interesting possibility that new drugs that block the reuptake, enhance the synthesis or inhibit the breakdown of endocannabinoids may be effective therapeutic agents. In the same manner that L-DOPA exhibits a markedly improved therapeutic profile compared with apomorphine for treating Parkinson's disease, drugs that would modify endocannabinoid action may likewise be observed to produce pain relief with fewer side effects.

In summary, there remains little doubt that cannabinoids inhibit nociceptive neurotransmission. Mounting evidence further implicates endocannabinoids in pain regulatory circuitry in the central nervous system and the periphery. Further work in this area offers hope for new pharmacotherapies for pain, especially in instances where opiates either lack efficacy or produce intolerable side effects, such as in neuropathic and cancer pain.

18. Herkenham M, Lynn AB, Johnson MR, Melvin LS, De Costa BR, Rice KC. Characterization and localization of cannabinoid receptors in rat brain: a quantitative in vitro autoradiographic study. J Neurosci 1991;11:563-83.

19. Mailleux P, Vanderhaeghen JJ. Distribution of neuronal cannabinoid receptor in the adult rat brain: a comparative receptor binding radioautography and in situ hybridization histochemistry. Neuroscience 1992;48:655-68.

20. Tsou K, Brown S, Sanudo-Pena MC, Mackie K, Walker JM. Immunohistochemical localization of cannabinoid CB1 receptors in rat central nervous system. Neuroscience 1998;83:393-411.

21. Ameri A. The effects of cannabinoids on the brain. Prog Neurobiol 1999;58:315-48.

22. Galiegue S, Mary S, Marchand J, et al. Expression of central and peripheral cannabinoid receptors in human immune tissues and leukocyte subpopulations. Eur J Biochem 1995;232:54-61.

23. Schatz AR, Lee M, Condie RB, Pulaski JT, Kaminski NE. Cannabinoid receptors $\mathrm{CB} 1$ and $\mathrm{CB} 2$ : a characterization of expression and adenylate cyclase modulation within the immune system. Toxicol Appl Pharmacol 1997;142:278-87.

24. Mackie K, Devane WA, Hille B. Anandamide an endogenous cannabinoid inhibits calcium currents as a partial agonist in N18 neuroblastoma cells. Mol Pharmacol 1993;44:498-503.

25. Howlett AC, Johnson MR, Melvin LS, Milne GM. Nonclassical cannabinoid analgetics inhibit adenylate cyclase: development of a cannabinoid receptor model. Mol Pharmacol 1988;33:297-302.

26. Hohmann AG, Herkenham M. Regulation of cannabinoid and mu opioid receptors in rat lumbar spinal cord following neonatal capsaicin treatment. Neurosci Lett 1998;252:13-6.

27. Hohmann AG, Briley EM, Herkenham M. Pre- and postsynaptic distribution of cannabinoid and mu opioid receptors in rat spinal cord. Brain Res 1999;20:822:17-25.

28. Hohmann AG, Herkenham M. Cannabinoid receptors undergo axonal flow in sensory nerves. Neuroscience 1999;92:1171-5.

29. Sanudo-Pena MC, Strangman NM, Mackie K, Walker J M, Tsou K. CB1 receptor localization in spinal cord and roots, dorsal root ganglion, and peripheral nerve. Acta Pharmacol Sinica 1999;12:1115-20.

30. Devane WA, Hanus L, Breuer A, et al. Isolation and structure of a brain constituent that binds to the cannabinoid receptor. Science 1992;258:1946-9.

31. Mechoulam R, Ben-Shabat S, Hanus L, et al. Identification of an endogenous 2-monoglyceride, present in canine gut that binds to cannabinoid receptors. Biochem Pharmacol 1995;50:83-90.

32. Sugiura T, Kondo S, Sukagawa A, et al. 2-Arachidonoylglycerol: a possible endogenous cannabinoid receptor ligand in brain. Biochem Biophys Res Commun 1995;215:89-97. 
33. Sanudo Pena MC, Walker JM. A novel neurotransmitter system involved in the control of motor behavior by the basal ganglia. Ann NY Acad Sci 1998;860:475-9.

34. Hohmann AG, Martin WJ, Tsou K, Walker JM. Inhibition of noxious stimulus-evoked activity of spinal cord dorsal horn neurons by the cannabinoid WIN 55,212-2. Life Sci 1995;56:2111-9.

35. Hohmann AG, Tsou K, Walker J M. Cannabinoid modulation of wide dynamic range neurons in the lumbar dorsal horn of the rat by spinally administered WIN55,212-2. Neurosci Lett 1998;257:1-4.

36. Hohmann AG, Walker JM. Cannabinoid suppression of noxious heatevoked activity in wide dyanamic range neuron in the lumbar dorsal horn of the rat. J Neurophysiol 1999;81:575-83.

37. Hohmann AG, Tsou K, Walker JM. Intrathecal cannabinoid administration suppresses noxious stimulus-evoked Fos protein-like immunoreativity in rat spinal cord: comparison with morphine. Acta Pharmacol Sin 1999;12:1132-6.

38. Martin WJ, Hohman AG, Walker JM. Suppression of noxious stimulus-evoked activity in the ventral posterolateral nucleus of the thalamus by the cannabinoid WIN 55,212-2: correlation between electrophysiological and antinociceptive effects. J Neurosci 1996;16:6601-11.

39. Strangman NM, Walker JM. The cannabinoid WIN 55, 212-2 inhibits the activity-dependent facilitation of spinal nociceptive responses. J Neurophysiol 1999;82:472-7.

40. Martin WJ, Lai NK, Patrick SL, Tsou K, Walker JM. Antinociceptive actions of WIN 55,212-2 following intraventricular administration in rats. Brain Res 1993;629:300-4.

41. Martin WJ, Patrick SL, Coffin PO, Tsou K, Walker JM. An examination of the central sites of action of cannabinoid-induced antinociception in the rat. Life Sci 1995;56:2103-10.

42. Martin WJ, Coffin PO, Attias E, Balinsky M, Tsou K, Walker JM. Anatomical basis for cannabinoid-induced antinociception as revealed by intracerebral microinjections. Brain Res 1999;822:237-42.

43. Martin WJ, Tsou K, Walker JM. Cannabinoid receptor-mediated inhibition of the rat tail-flick reflex after microinjection into the rostral ventromedial medulla. Neurosci Lett 1998;232:33-6.

44. Proudfit HK. Pharmacologic evidence for the modulation of nociception by noradrenergic neurons. Prog Brain Res 1988;77:357-70.

45. Meng ID, Manning BH, Martin WJ, Fields HL. An analgesia circuit activated by cannabinoids. Nature 1998;395:381-3.

46. Strangman NM, Patrick SL, Hohmann AG, Tsou K, Walker JM.
Evidence for a role of endogenous cannabinoids in the modulation of acute and tonic pain sensitivity. Brain Res 1998;813:323-8.

47. Richardson JD, Aanonsen L, Hargreaves KM. SR141716A, a cannabinoid receptor antagonist, produces hyperalgesia in untreated mice. Eur J Pharmacol 1997;319:R3-4.

48. Richardson JD, Aanonsen L, Hargreaves KM. Antihyperalgesic effects of spinal cannabinoids. Eur J Pharmacol 1998;345:145-53.

49. Richardson JD, Aanonsen L, Hargreaves KM. Hypoactivity of the spinal cannabinoid system results in NMDA-dependent hyperalgesia. J Neurosci 1998;18:451-7.

50. Walker JM, Huang SM, Strangman NM, Tsou K, Sanudo-Pena MC. Pain modulation by release of the endogenous cannabinoid anandamide. Proc Natl Acad Sci USA 1999;96:12198-203.

51. Welch SP, Stevens DL. Antinociceptive activity of intrathecally administered cannabinoids alone and in combination with morphine in mice. J Pharmacol Exp Ther 1992;262:10-8.

52. Richardson JD, Kilo S, Hargreaves KM. Cannabinoids reduce hyperalgesia and inflammation via interaction with peripheral CB1 receptors. Pain 1998;75:111-9.

53. Calignano A, La Rana G, Giuffrida A, Piomelli D. Control of pain initiation by endogenous cannabinoids. Nature 1998;394:277-81.

54. Joy JE, Watson SJ, Benson JA Jr, eds. Marijuana and Medicine: Assessing the Science Base. Washington: National Academy Press, 1999.

55. Noyes R Jr, Brunk SF, Baram DA, Canter A. Analgesic effect of delta-9-tetrahydrocannabinol. J Clin Pharmacol 1975;1:139-43.

56. Noyes Jr R, Brunk S, Avery DH, Canter A. The analgesic properties of delta-9-tetrahydrocannabinol and codeine. Clin Pharmacol Ther 1975;18:84-9.

57. Raft D, Gregg J, Ghia J, Harris L. Effects of intravenous tetrahydrocannabinol on experimental and surgical pain. Psychological correlates of the analgesic response. Clin Pharmacol Ther 1977;21:26-33.

58. Burstein SH, Friderichs E, Kogel B, Schneider J, Selve N. Analgesic effects of 1',1' dimethylheptyl-delta8-THC-11-oic acid (CT3) in mice. Life Sci 1998;63:161-8.

59. Rhee MH, Vogel Z, Barg J, et al. Cannabinol derivatives: binding to cannabinoid receptors and inhibition of adenylylcyclase. J Med Chem 1997;40:3228-33.

60. Childers SR, Breivogel CS. Cannabis and endogenous cannabinoid systems. Drug Alcohol Depend 1998;51:173-87.

61. Ueda N, Yamamoto S. Anandamide amidohydrolase (fatty acid amide hydrolase). Prostaglandins Other Lipid Mediat 2000;61:19-28. 


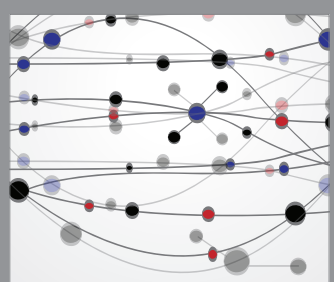

The Scientific World Journal
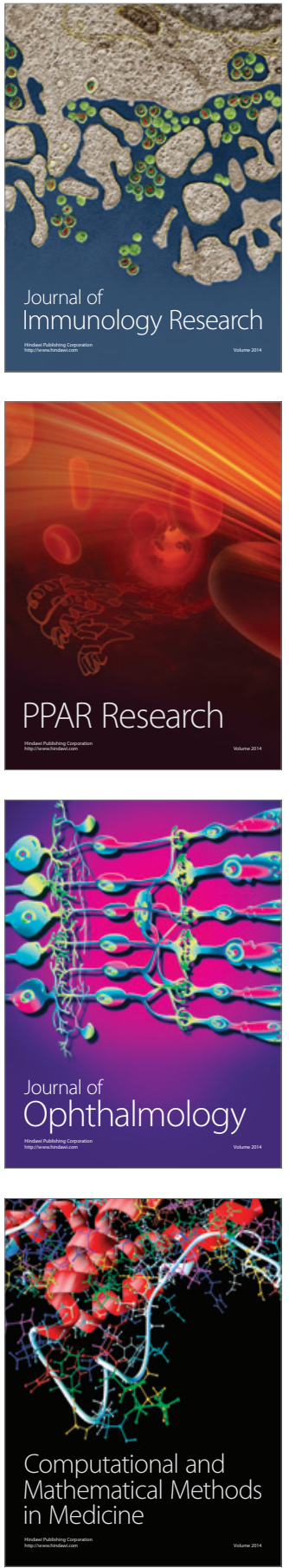

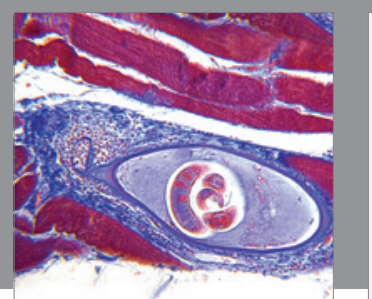

Gastroenterology Research and Practice

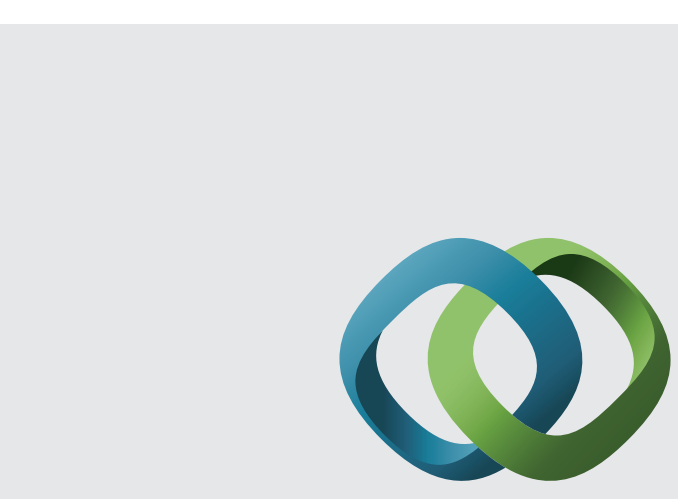

\section{Hindawi}

Submit your manuscripts at

http://www.hindawi.com
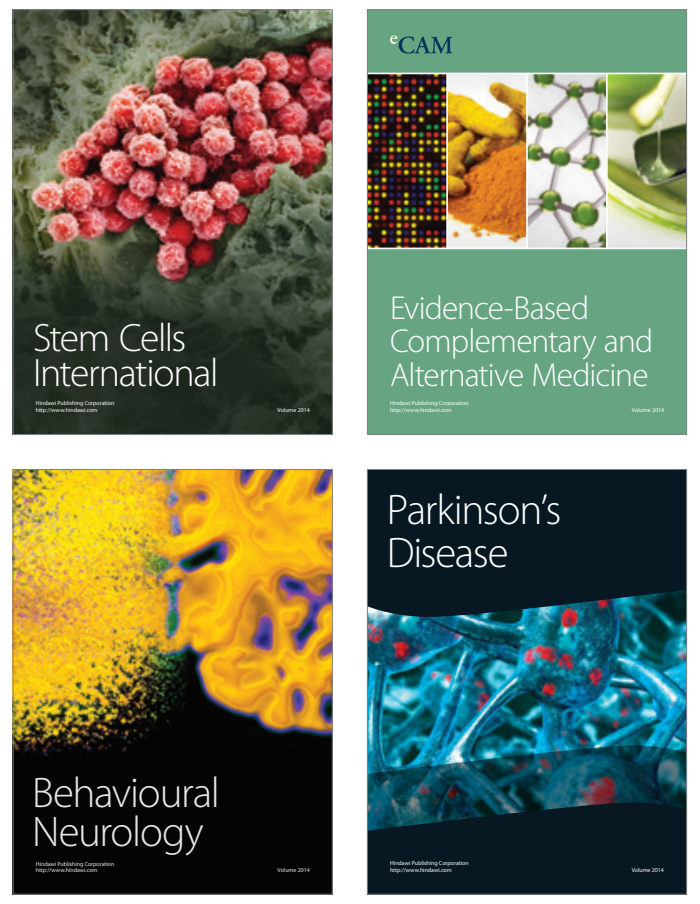
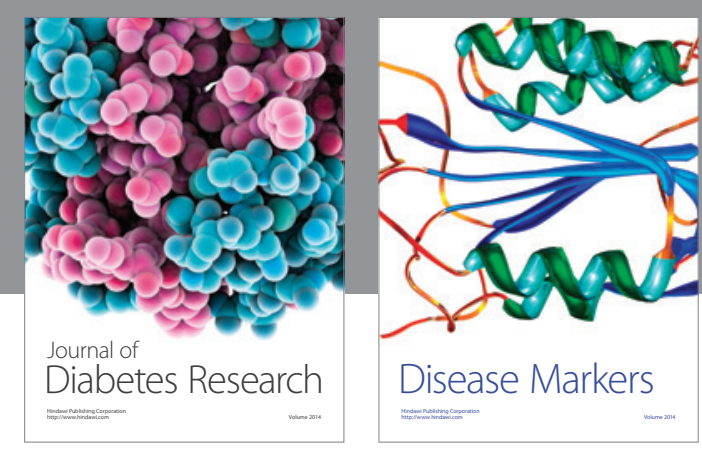

Disease Markers
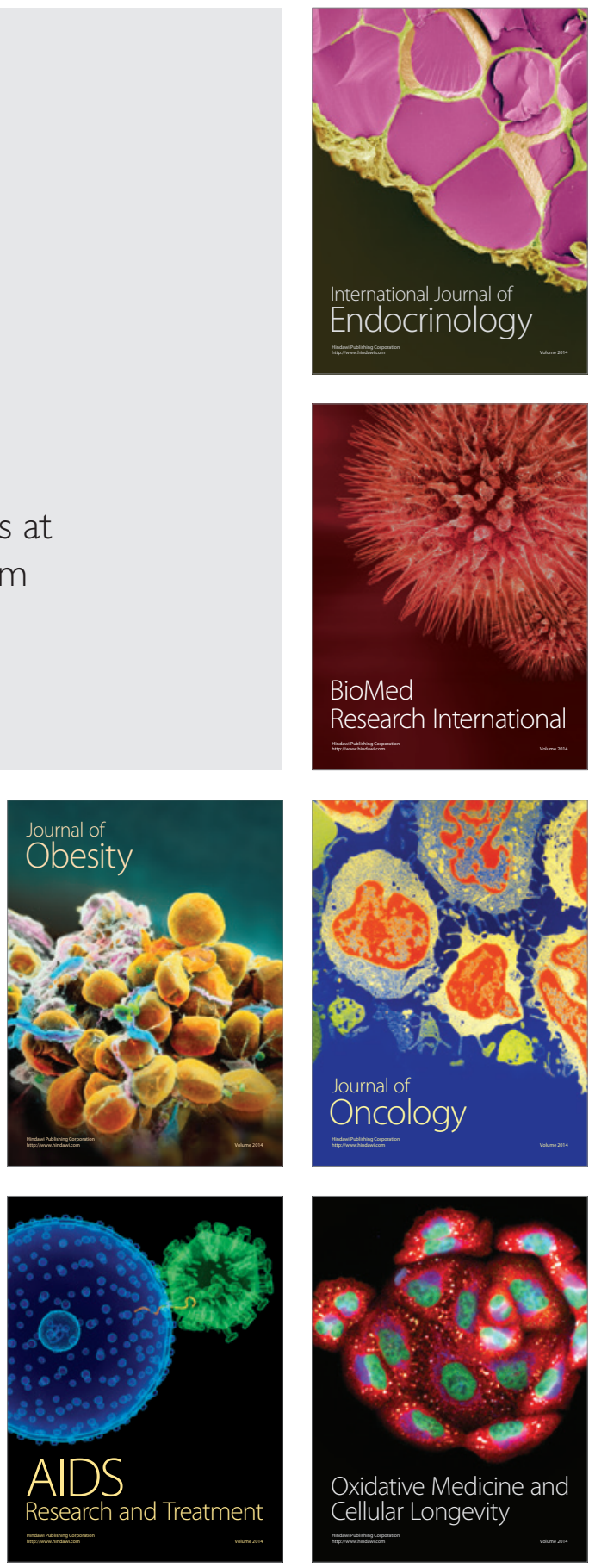